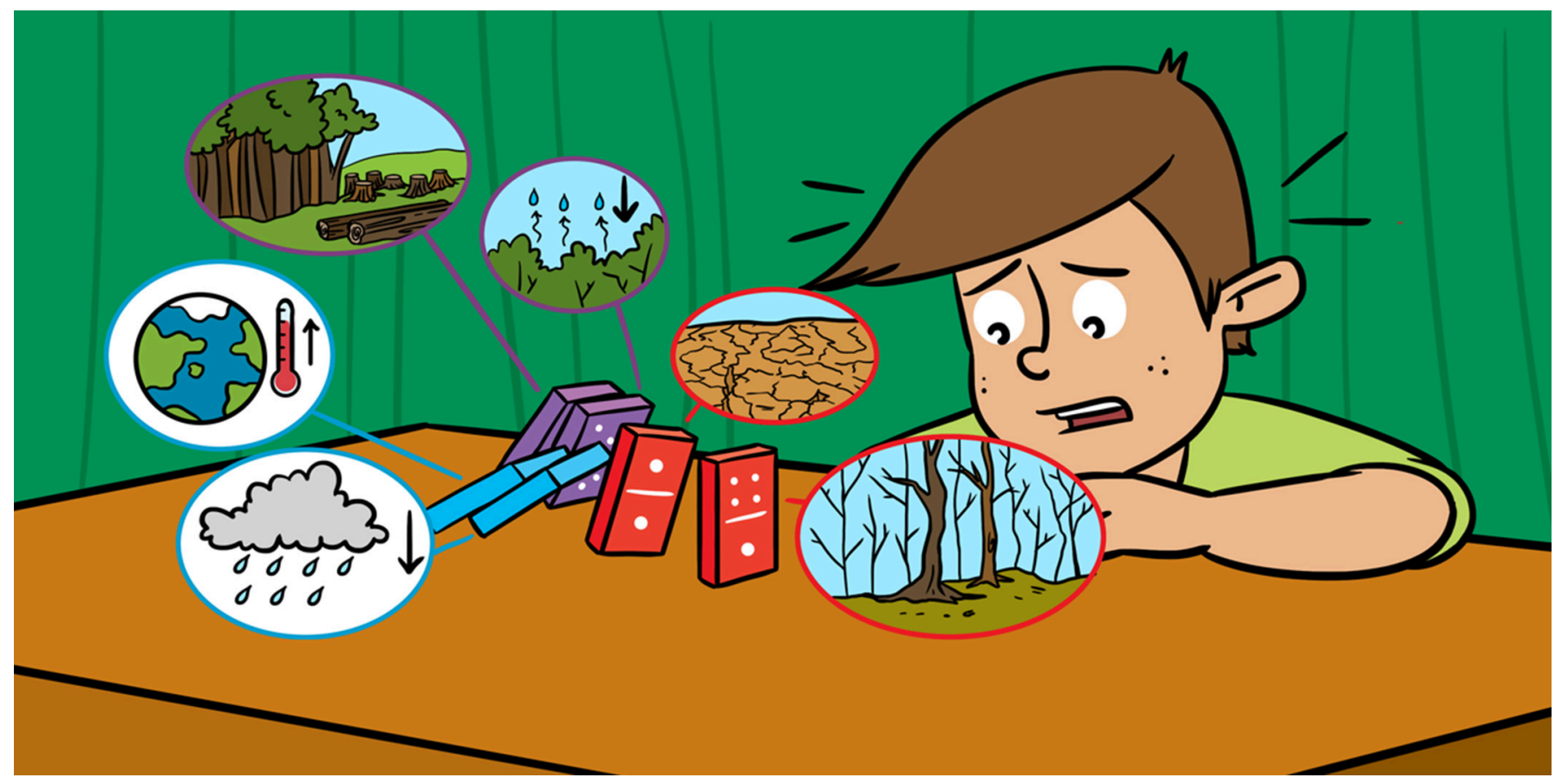

\title{
TIPPING POINTS: CLIMATE SURPRISES
}

\author{
Sofia Palazzo Corner ${ }^{1 *}$ and Chris D. Jones ${ }^{2+}$ \\ ${ }^{1}$ Centre for Environmental Policy, Imperial College London, London, United Kingdom \\ ${ }^{2}$ Met Office Hadley Centre, Exeter, United Kingdom
}

\section{YOUNG REVIEWER:}

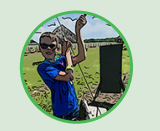

\section{DAVID}

AGE: 11

\section{TIPPING POINT}

A threshold in a system which, when passed, results in large changes. The edge of a hill is an example of a tipping point-where passing the edge leads you from the top to the bottom.
We know that the more greenhouse gases are released, the more the world warms. But, at a certain point, could a small amount of extra greenhouse gas cause a very big change in the climate? And could this big change be irreversible? When a small change causes a very large (and long-term) effect, we call this a tipping point. Scientists are trying to understand whether tipping points exist in the Earth's climate system, and if so, what impact these could have.

\section{WHAT IS A TIPPING POINT?}

When a very small change causes a large, long-term effect, we call this a tipping point. In scientific language, we say that the system is pushed from one "state" to another. To understand this definition, let's look at an example of a tipping point from our everyday lives. Imagine riding a bike along the top of a hill (Figure 1). Each time you push the pedals, you move a little further forward, until one push sends you that crucial inch closer to the edge, and suddenly you are rolling irreversibly down the hill, all the way to the bottom. By making that last push on the pedals, you pass the threshold that takes you from one state-being at the top of the hill-to another state-being at the bottom. 
Figure 1

When you ride your bike along the top of a hill, the last push of the pedals takes you past the tipping point, sending you irreversibly all the way down to the bottom.

\section{THRESHOLD}

The value which must be exceeded for a system to move from one state to another.

SELF-REINFORCING FEEDBACK LOOP

A process which gets stronger the more it happens. The melting and shrinking of the Greenland ice sheet is an example of a self-reinforcing feedback loop.

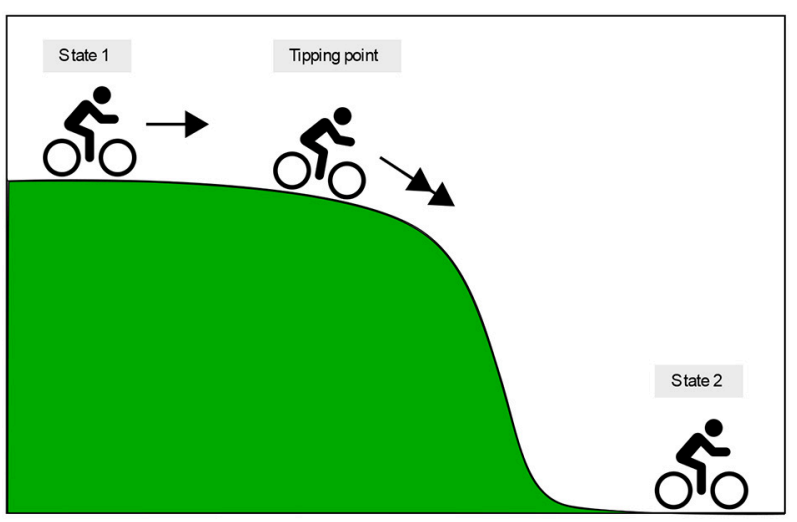

Figure 1

Scientists are working to understand whether tipping points exist in the Earth's climate system, and if so, what sorts of global impacts tipping points might have in the future. We will now describe the parts of Earth's climate system where this threshold behaviour seems most likely to happen.

\section{A TIPPING POINT FOR ICE SHEETS}

The Earth has two big ice sheets: the Greenland ice sheet in the north, and the Antarctic ice sheet in the south. Let's take the Greenland ice sheet as an example.

The Greenland ice sheet is a relic from the last ice age-this means it did not form in the climate we have today but is instead left over from when the climate was much colder. The Greenland ice sheet is so thick that it reaches an altitude of over $2 \mathrm{~km}$ above sea level. At this height, the air is much colder than at sea level, helping the ice to stay frozen. In the past, the air has been cold enough to stop the ice from melting too quickly, allowing the snow falling on the surface of the ice sheet to replace any melting ice lost to the ocean. However, as more heat has been trapped in the Earth by greenhouse gases in the atmosphere, the air has warmed, melting the ice sheet faster than it can be replaced by the falling snow.

As the ice melts, the ice sheet shrinks-it gets smaller and shorter. At these lower altitudes, the ice sheet is exposed to warmer air. The more the ice melts, the shorter the ice sheet gets, which causes more ice to melt, lowering the ice sheet further, causing more heating, and so on (Figure 2) [1]. This is known as a self-reinforcing feedback loop-the more it happens, the worse it gets. At a critical point, scientists think the ice sheet will pass a threshold where it irreversibly moves from a state with permanent ice to a state without it - the ice sheet will pass a tipping point, after which it will inevitably disappear completely [2]. 
Figure 2

The melting of the Greenland ice sheet and an example of a self-reinforcing loop. As the climate warms, the ice sheet melts and gets shorter. At lower altitudes, the air is warmer, so the ice sheet shrinks even more. The tipping point would be the threshold where the ice will inevitably continue to melt until it completely disappears.

\section{AMAZON DIEBACK}

The loss of biomass due to climate change, such as changing rainfall patterns and increased wildfires.

\section{CARBON SINK}

Something that absorbs more carbon than it releases, thus removing carbon from the atmosphere. Rainforests are an example of a carbon sink.

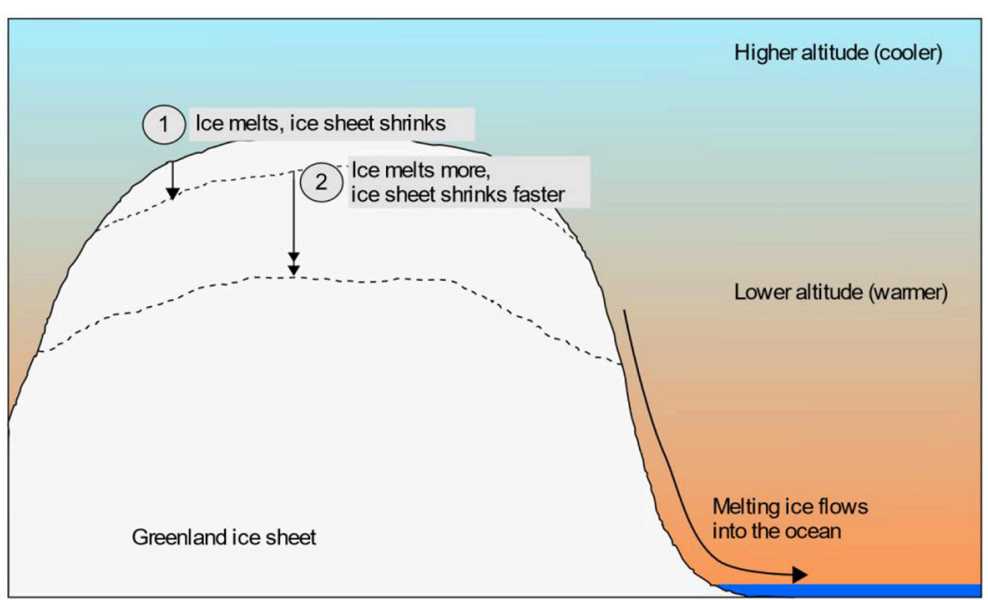

Figure 2

\section{A TIPPING POINT FOR THE LAND}

The Amazon rainforest is one of Earth's biggest natural ecosystems. The Amazon absorbs so much carbon dioxide that it is sometimes known as the lungs of the Earth. Without the Amazon, there would be a lot more carbon dioxide stuck in the atmosphere. As you might have guessed from the name, a rainforest requires a lot of rain. The Amazon is so enormous that it creates up to half of its own rainfall, just from the water evaporating from the plants and soil [3]. Without enough rainfall, the rainforest becomes vulnerable to big changes.

As the climate warms, patterns of rainfall change as well. Climate models predict a reduction in rain over the Amazon as global temperatures rise. To make matters worse, the Amazon is also shrinking due to deforestation (humans cutting down trees), which in turn reduces how much rain the rainforest can produce from its own evaporation. If there is not enough rain and the Amazon dries too much, this could cause the rainforest to die back, meaning the trees would die and not regrow. Instead, the rainforest would be replaced by grassland and savannah (Figure 3) [4, 5].

Amazon dieback would remove a large carbon sink from the Earth's climate system, meaning that more of our greenhouse gases would stay in the atmosphere, heating the Earth further and faster. The point at which there are not enough trees in the Amazon, or there is not enough rain, is an example of a possible tipping point on the land. 
Figure 3

Changing

rainfall patterns and deforestation could result in a tipping point for the Amazon rainforest. As the number of trees is reduced, rainfall over the Amazon is also reduced. Eventually, this could result in Amazon dieback, in which trees are replaced by grasslands. Since the Amazon is an important carbon sink, Amazon dieback could disturb the Earth's climate system.

\section{ATLANTIC}

MERIDIONAL

OVERTURNING

CIRCULATION

(AMOC)

A system of currents in the Atlantic Ocean, circulating water from the tropics to the northern Atlantic.

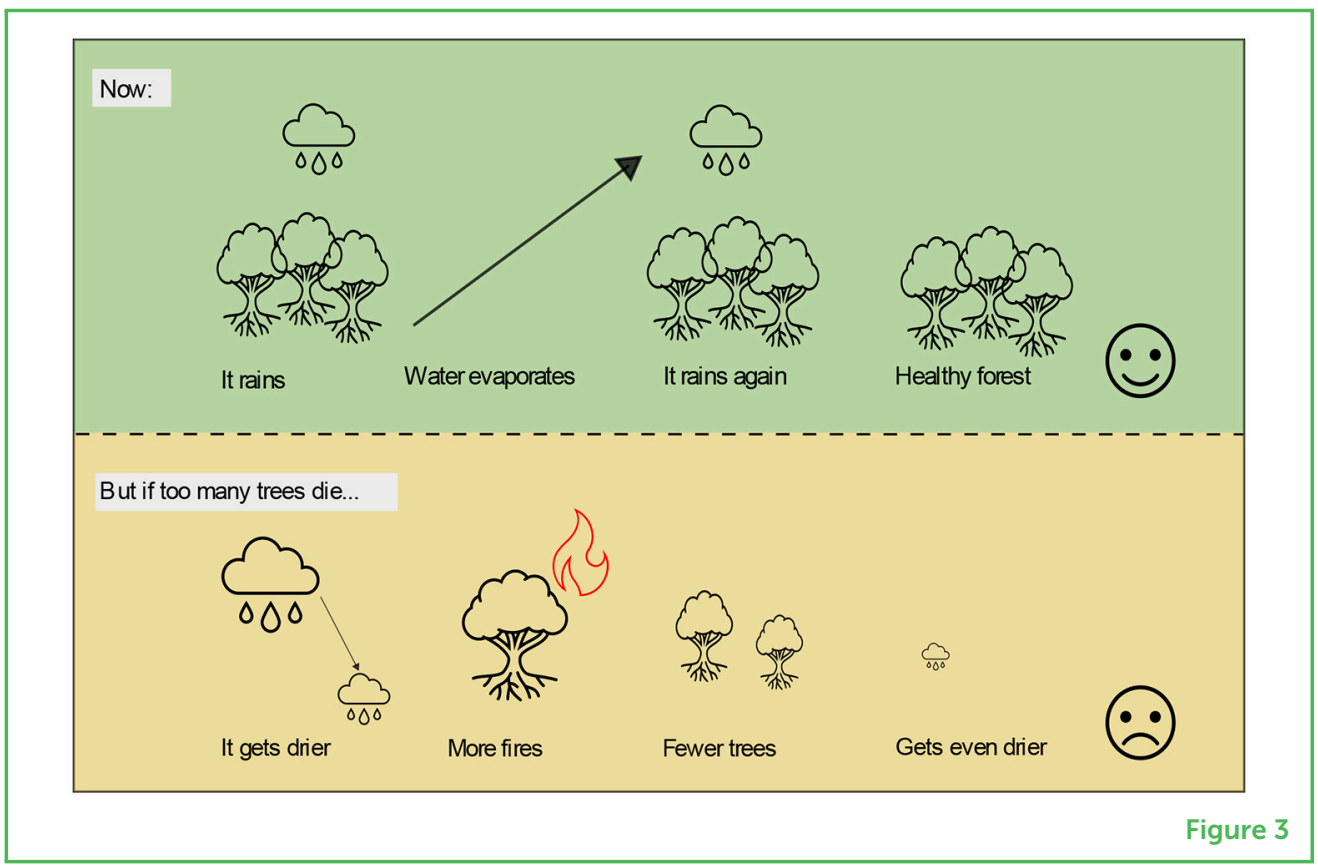

\section{A TIPPING POINT FOR THE OCEAN}

In the ocean, there is a large set of water currents called the Atlantic meridional overturning circulation (AMOC). These currents carry water from the tropics (near the equator) north toward the Arctic, where the water cools, sinks, and then travels back toward the tropics. This circulation drives itself-the more water that sinks in the north, the more water is brought up from the tropics to travel north and sink again, in turn. However, as the Greenland ice sheet melts and rainfall increases, a larger volume of cold, fresh water flows into the northern part of the Atlantic Ocean [6]. This freshwater mixes with the salt water, making it lighter and less likely to sink. This weakens the flow of water, causing the AMOC to slow down.

Climate scientists and oceanographers are trying to understand whether this slowing could ever become a complete shutdown, 'meaning that the overturning circulation would stop altogether. The AMOC is responsible for the mild climate in Western Europe-without it, the temperatures and rainfall there would be quite different. These enormous flows of water are also important for absorbing heat and carbon. Scientists are working to understand whether there is a critical point-a threshold-where the slowing down of the AMOC could tip into an irreversible shutting down [1]. This is an example of a potential tipping point in the ocean.

\section{WHY SHOULD WE WORRY ABOUT TIPPING POINTS?}

If tipping points exist in the Earth's climate system, could one tipping point set off the rest, like a line of dominoes? This is a very worrying 
possibility. Tipping elements can cause abrupt change or slow change but, in either case, passing the threshold causes the system to move inevitably toward a new state. Triggering a tipping point in one part of the Earth's climate system may make it more likely that we approach a threshold in another part. This effect of one tipping point causing another is called a tipping point cascade [7].

Will the Earth reach any tipping points soon? The Earth's climate system is very complex. Scientists use lots of different pieces of evidence to understand what will happen in the future; they build climate models and make observations of changes in particular places, like the ocean. At this point, we know that more greenhouse gases mean more warming, but we do not know exactly how much greenhouse gases would result in a tipping point for the ice sheets or dieback of the Amazon rainforest. This means there is still a lot of uncertainty about tipping points, when they could happen, and what they would mean [8].

However, just knowing that tipping points might happen could be enough to influence what we do today. Since the consequences of the tipping points we have described are so serious, even a small probability of reaching a tipping point may be a risk we are unwilling to take [9]. This is one of the main reasons why all the world's governments are making pledges to try to limit climate change so that we reduce the risks of these serious impacts.

TIPPING POINT

\section{CASCADES}

Where the triggering of one tipping point causes changes in the climate which trigger another tipping point, and so on.
Scientists will continue working to understand whether tipping points exist in the Earth system, and if so, when they might be triggered and what might happen if they were. The more we learn about tipping points, the better we can plan ways to avoid them, or at least how to manage them if they do occur. The possibility of tipping points and tipping point cascades is a very good reason for us to take lots of positive action today to reduce our greenhouse gas emissions.

\section{REFERENCES}

1. Good, P, Bamber, J., Halladay, K., Harper, A. B., Jackson, L. C., Kay, G., et al. 2018. Recent progress in understanding climate thresholds: Ice sheets, the Atlantic meridional overturning circulation, tropical forests and responses to ocean acidification. Progr Phys Geogr. 42:24-60. doi: 10.1177/0309133317751843

2. Robinson, A., Calov, R., and Ganopolski, A. 2012. Multistability and critical thresholds of the Greenland ice sheet. Nat Clim Change. 2:429-32. doi: $10.1038 /$ nclimate1449

3. van der Ent, R. J., Savenije, H. H. G., Schaefli, B., and Steele-Dunne, S. C. 2010. Origin and fate of atmospheric moisture over continents. Water Resourc Res. 46, W09525. doi: 10.1029/2010WR009127

4. Lovejoy, T. E., and Nobre, C. 2018. Amazon tipping point. Sci Adv. 4:eaat2340. doi: $10.1126 /$ sciadv.aat 2340 
5. Staal, A., Fetzer, I., Wang-Erlandsson, L., Bosmans, J. H. C., Dekker, S. C., van Nes, E. H., et al. 2020. Hysteresis of tropical forests in the 21st century. Nat Commun. 11:4978. doi: 10.1038/s41467-020-18728-7

6. Lohmann, J., and Ditlevsen, P. D. 2021. Risk of tipping the overturning circulation due to increasing rates of ice melt. Proc Natl Acad Sci USA. 118:e2017989118. doi: 10.1073/pnas.2017989118

7. Steffen, W., Rockström, J., Richardson, K., Lenton, T. M., Folke, C., Liverman, D., et al. 2018. Trajectories of the earth system in the anthropocene. Proc Natl Acad Sci USA. 115:8252-9. doi: 10.1073/pnas.1810141115

8. Wang, S., and Hausfather, Z. 2020. ESD reviews: mechanisms, evidence, and impacts of climate tipping elements. Earth Syst. Dynam. Disc. 1-93. doi: 10.5194/esd-2020-16

9. Lenton, T. M., Rockstrom, J., Gaffney, O., Rahmstorf, S., Richardson, K., Steffen, W., et al. 2019. Climate tipping points - too risk to bet against. Nature. 575:592-5. doi: 10.1038/d41586-019-03595-0

SUBMITTED: 30 April 2021; ACCEPTED: 25 October 2021;

PUBLISHED ONLINE: 18 November 2021.

EDITOR: Dominik K. Großkinsky, Austrian Institute of Technology (AIT), Austria

CITATION: Palazzo Corner S and Jones CD (2021) Tipping Points: Climate Surprises. Front. Young Minds 9:703610. doi: 10.3389/frym.2021.703610

CONFLICT OF INTEREST: The authors declare that the research was conducted in the absence of any commercial or financial relationships that could be construed as a potential conflict of interest.

COPYRIGHT () 2021 Palazzo Corner and Jones. This is an open-access article distributed under the terms of the Creative Commons Attribution License (CC BY). The use, distribution or reproduction in other forums is permitted, provided the original author(s) and the copyright owner(s) are credited and that the original publication in this journal is cited, in accordance with accepted academic practice. No use, distribution or reproduction is permitted which does not comply with these terms.

\section{YOUNG REVIEWER}

\section{DAVID, AGE: 11}

I like fishing and being outdoors. My favourite food is fried catfish with tarter sauce. My favourite colour is deep metallic green. My favourite movie is Harry Potter and the prisoner of Azkaban. 


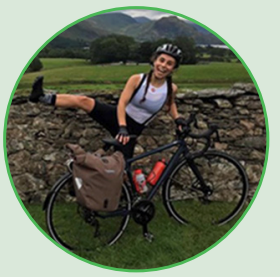

\section{AUTHORS}

\section{SOFIA PALAZZO CORNER}

Sofia Palazzo Corner is a Ph.D., student at Imperial College London, researching low probability, high-impact processes in the Earth's climate system-some of which involve tipping points. She is co-supervised by Dr. Chris D. Jones. Sofia has an undergraduate degree in physics and a master's degree in applied mathematics. She is a keen cyclist and knows all about riding down hills too quickly. *s.palazzo-corner19@imperial.ac.uk

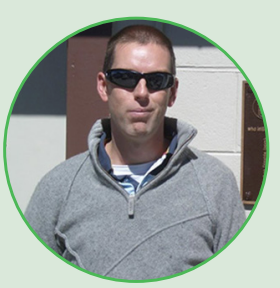

\section{CHRIS D. JONES}

Dr. Chris D. Jones is a climate researcher at the Met Office Hadley Centre in Exeter in the UK. He has over 25 years of experience of writing computer programmes to model how climate affects our natural ecosystems and how the carbon cycle helps reduce the amount of $\mathrm{CO}_{2}$ pollution in the atmosphere. He leads a research programme with partners in Brazil and has visited research sites in the Amazon rainforest. The photo here is on top of the Mauna Loa volcano in Hawaii, where $\mathrm{CO}_{2}$ is measured. ${ }^{\dagger}$ orcid.org/0000-0002-7141-9285 